Linköping Studies in Science and Technology, Thesis No. 1619

Licentiate Thesis

\title{
High-Temperature Behaviour of Austenitic Alloys
}

-Influence of Temperature and Strain Rate on

Mechanical Properties and Microstructural Development

\section{Mattias Calmunger}

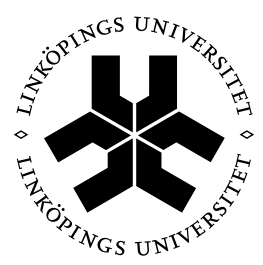

\section{Linköping University INSTITUTE OF TECHNOLOGY}

LIU-TEK-LIC-2013:53

Division of Engineering Materials

Department of Management and Engineering

Linköping University, SE-581 83, Linköping, Sweden

http://www.liu.se

Linköping, September 2013 
Opponent: Professor Göran Engberg, Dalarna University, Falun, Sweden.

Date: 10:15, November 1, 2013

Room: ACAS, Linköping University

Cover:

Dynamic recrystallization in AISI 316L slow strain rate tensile tested at elevated temperature.

Printed by:

LiU-Tryck, Linköping, Sweden, 2013

ISBN 978-91-7519-512-4

ISSN 0280-7971

Distributed by:

Linköping University

Department of Management and Engineering

SE-581 83, Linköping, Sweden

\section{(ㄱ) 2013 Mattias Calmunger}

This document was prepared with $\mathrm{H}_{\mathrm{E}} \mathrm{T} \mathrm{X}$, October 2, 2013 


\section{Abstract}

The global increase in energy consumption and the global warming from greenhouse gas emission creates the need for more environmental friendly energy production processes. Biomass power plants with higher efficiency could generate more energy but also reduce the emission of greenhouse gases, e.g. $\mathrm{CO}_{2}$. Biomass is the largest global contributor to renewable energy and offers no net contribution of $\mathrm{CO}_{2}$ to the atmosphere. One way to increase the efficiency of the power plants is to increase temperature and pressure in the boiler parts of the power plant.

The materials used for the future biomass power plants, with higher temperature and pressure, require improved properties, such as higher yield strength, creep strength and high-temperature corrosion resistance. Austenitic stainless steels and nickel-base alloys have shown good mechanical and chemical properties at the operation temperatures of today's biomass power plants. However, the performance of austenitic stainless steels at the future elevated temperatures is not fully understood.

The aim of this licentiate thesis is to increase our knowledge about the mechanical performance of austenitic stainless steels at the demanding conditions of the new generation power plants. This is done by using slow strain rate tensile deformation at elevated temperature and long term hightemperature ageing together with impact toughness testing. Microscopy is used to investigate deformation, damage and fracture behaviours during slow deformation and the long term influence of temperature on toughness in the microstructure of these austenitic alloys. Results show that the main deformation mechanisms are planar dislocation deformations, such as planar slip and slip bands. Intergranular fracture may occur due to precipitation in grain boundaries both in tensile deformed and impact toughness tested alloys. The shape and amount of $\sigma$-phase precipitates have been found to strongly influence the fracture behaviour of some of the austenitic stainless steels. In addition, ductility is affected differently by temperature depending on alloy tested and dynamic strain ageing may not always lead to a lower ductility. 



\section{Acknowledgement}

This research has been financially supported by AB Sandvik Materials Technology in Sandviken, Sweden and the Swedish Energy Agency through the Research Consortium of Materials Technology for Thermal Energy Processes, Grant No. KME-501, for which they are all greatly acknowledged.

Many thanks to my supervisors Sten Johansson, Guocai Chai and Johan Moverare for their support, guidance and encouragement during this project. I would also like to thank all my colleagues at the division of Engineering Materials for fruitful discussions and creating an enjoyable working environment. The technical support from Annethe Billenius, Bo Skoog, Patrik Härnman, Per Johansson and Peter Karlsson is greatly acknowledged. Agora Materiae and the Strategic Faculty Grant AFM (SFO-MAT-LiU\#2009-00971) at Linköping University are also acknowledged.

In addition, a collective acknowledgement goes out to my colleagues at Sandvik Materials Technology, especially to Jan Högberg, Jerry Lindqvist and Håkan Nylén for all their help and assistance.

Finally, I would like to thank my family and especially my dear wife and son, for all their patient and support.

\section{Mattias Calmunger}

Linköping, September 2013 



\section{List of Papers}

In this thesis, the following papers have been included:

I. M. Calmunger, G. Chai, S. Johansson and J. Moverare, Deformation and damage behaviours of austenitic alloys in the dynamic strain ageing regime, Submitted for publication.

II. M. Calmunger, G. Chai, S. Johansson and J. Moverare, Influence of deformation rate on mechanical response of an AISI 316L austenitic stainless steel, Accepted for presentation at THERMEC'2013, Las Vegas (USA), 2013, To appear in Advanced Materials Research or Materials Science Forum.

III. M. Calmunger, G. Chai, S. Johansson and J. Moverare, Mechanical behaviours of Alloy 617 with varied strain rate at high temperatures, Accepted for presentation at THERMEC'2013, Las Vegas (USA), 2013, To appear in Advanced Materials Research or Materials Science Forum.

IV. M. Calmunger, G. Chai, S. Johansson and J. Moverare, Damage and fracture behaviours in aged austenitic materials during high temperature slow strain rate testing, Presented at MSMF7, Brno (Czech Republic), 2013, To appear in Key Engineering Materials.

V. M. Calmunger, R. L. Peng, G. Chai, S. Johansson and J. Moverare, Advanced microstructure studies of an austenitic material using EBSD in elevated temperature in-situ tensile testing in SEM, Presented at MSMF7, Brno (Czech Republic), 2013. To appear in Key Engineering Materials.

VI. M. Calmunger, G. Chai, S. Johansson and J. Moverare, Influence of high temperature ageing on the toughness of advanced heat resistant materials, Presented at ICF13, Beijing (China), 2013. 
Own contribution to the papers included:

In all papers above, I have been the main contributor of the microstructure investigation, evaluation and manuscript writing. In addition, I have performed all the slow strain rate tensile testing in the listed papers and also conducted the in-situ tensile testing. All other mechanical testing have been performed at AB Sandvik Materials Technology in Sandviken, Sweden.

Papers not included in this thesis:

VII M. Calmunger, G. Chai, S. Johansson and J. Moverare, Damage and fracture behaviours in advanced heat resistant materials during slow strain rate test at high temperature, Presented at ICF13, Beijing (China), 2013.

VIII M. Lundberg, M. Calmunger and R. L. Peng, In-situ SEM/EBSD study of deformation and fracture behaviour of flake cast iron, Presented at ICF13, Beijing (China), 2013.

IX M. Calmunger, G. Chai, S. Johansson and J. Moverare, Influence of dynamic strain ageing on damage in austenitic stainless steels, Presented at ECF19, Kazan (Russia), 2012. 


\section{Contents}

Abstract

Acknowledgement $\quad$ v

List of Papers vii

$\begin{array}{ll}\text { Contents } & \text { ix }\end{array}$

Abbreviation $\quad$ xi

Part I Background and Theory xiii

1 Introduction $\mathbf{1}$

1.1 Introduction to the research project . . . . . . . . . . . . . 1

1.2 Background ....................... . . . 1

1.3 Purpose of research and future work . . . . . . . . . . . 2

1.4 Structure of the thesis . . . . . . . . . . . . . . 3

2 Austenitic alloys 5

2.1 Austenitic stainless steels . . . . . . . . . . . . . . 5

2.1.1 Main alloying elements . . . . . . . . . . . . . 6

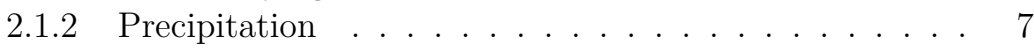

2.2 Nickel-base alloys . . . . . . . . . . . . . . . . . . . . . . . . . 8

3 Microstructural mechanisms and phenomena 9

3.1 Deformation mechanisms . . . . . . . . . . . . . . 9

3.1.1 Dislocation movement . . . . . . . . . . . . . . . 9

3.1.2 Twinning .................... . . . 10

3.2 Softening phenomena . . . . . . . . . . . . . . . . . 11

3.2.1 Dynamic recovery . . . . . . . . . . . . . 11 
3.2.2 Dynamic recrystallization . . . . . . . . . . . 12

3.3 Dynamic strain ageing . . . . . . . . . . . . . . . 12

4 Experimental and analytical methods $\quad 15$

4.1 Material . . . . . . . . . . . . . . . . . . . . . 15

4.2 Tensile deformation . . . . . . . . . . . . . . . . . . . 15

4.3 Impact toughness testing . . . . . . . . . . . . . . . . . 18

4.4 Microscopy . . . . . . . . . . . . . . . . . . . . . . . . . . 18

4.4.1 Specimen preparation . . . . . . . . . . . . . 18

4.4 .2 Scanning electron microscopy . . . . . . . . . . . . 19

5 Summary of appended papers 23

6 Conclusions 27

$\begin{array}{ll}\text { Bibliography } & 29\end{array}$

Part II Papers Included 35

Paper I: Deformation and damage behaviours of austenitic alloys in the dynamic strain ageing regime 39

Paper II: Influence of deformation rate on mechanical response of an AISI 316L austenitic stainless steel 57

Paper III: Mechanical behaviours of Alloy 617 with varied strain rate at high temperatures

Paper IV: Damage and fracture behaviours in aged austenitic materials during high temperature slow strain rate testing 73

Paper V: Advanced microstructure studies of an austenitic material using EBSD in elevated temperature in-situ tensile testing in SEM

Paper VI: Influence of high temperature ageing on the toughness of advanced heat resistant materials 


\title{
Abbreviation
}

\author{
AUSC advanced ultra-super critical \\ BCC body-centred cubic \\ BSE backscattered electron \\ DB deformation band \\ DRV dynamic recovery \\ DRX dynamic recrystallization \\ DSA dynamic strain ageing \\ EBSD electron backscatter diffraction \\ ECCI electron channeling contrast imaging \\ EDS energy-dispersive system \\ FCC face-centred cubic \\ FEG field emission gun \\ FIB focused ion beam \\ GAM grain average misorientation \\ GB grain boundary \\ IPF inverse pole figure \\ LAGB low angle grain boundary \\ LCF low cycle fatigue \\ PLC Portevin-Le Châtelier \\ RT room temperature \\ SB slip band \\ SEM scanning electron microscopy \\ SF Schmid factor \\ SFE stacking-fault energy \\ SSRT slow strain rate tensile testing \\ TB twin boundary \\ TWIP twinning induced plasticity
}



Part I

Background and Theory 



\section{1 \\ Introduction}

\subsection{Introduction to the research project}

This licentiate thesis is a part of the ongoing research project Long term high temperature behaviour of advanced heat resistant materials. The project started with a M.Sc. thesis work [1] in the summer of 2011 and is carried out in a strong collaboration between Linköping University and AB Sandvik Materials Technology in Sandviken, Sweden. It is financed through the Research Consortium of Materials Technology for Thermal Energy Processes (KME), grant no. KME-501. The purpose of research within KME is to make thermal energy processes more effective and is financially supported by both industries (60\%) and the Swedish Energy Agency (40\%).

\subsection{Background}

The research project is mainly concerned with two different groups of austenitic alloys, austenitic stainless steels and nickel-base alloys. Some of them are used in the biomass power plants of today and some are potential materials for the next generations biomass power plant [2]. Biomass is the largest global contributor to renewable energy and has a great potential to expand in the production of heat and electricity [3]. It is a sustainable fuel because it gives no net contribution of $\mathrm{CO}_{2}$ to the atmosphere and it can be considered endless [3, 4]. However, the global increase in energy consumption and the increase in emissions of greenhouse gases (e.g. $\mathrm{CO}_{2}$ ) causing global warming, make needs for both an increase in energy production and a reduction of greenhouse gas emission $[3,5]$. One way to accomplish both needs is to increase the efficiency of biomass power plants, which could be reached 
by increasing temperature and pressure in the boiler sections [6]. Thus, the requirement of more energy production is met and since biomass has no net contribution of $\mathrm{CO}_{2}$ to the atmosphere less emissions of greenhouse gases is the result.

Both groups of the austenitic alloys show good mechanical and chemical properties at the operation temperatures of today's biomass power plants [2]. However, the materials used for the future biomass power plants with higher efficiency are required to display improved properties as higher yield strength, creep strength and high-temperature corrosion resistance. The performance of austenitic stainless steels at these elevated temperatures is not fully understood, but the nickel-base alloys are already operating at such conditions in other applications and the group of nickel-base alloys is a possible option $[2,7]$. The nickel-base alloys are more expensive than the austenitic stainless steels and the austenitic stainless steels are therefore an interesting option to investigate as a material for the future biomass power plants. The austenitic stainless steels are of main concern in this thesis and the nickel-base alloys acting reference materials.

\subsection{Purpose of research and future work}

In the general goals of KME's program period 2010-2013 it is stated that:

"The program will contribute to the conversion to a sustainable energy system by development of more effective energy processes."

The purposes of this research project is to improve knowledge regarding tensile deformation and cracking behaviour during very slow deformation and the influence of long term ageing and tough environments, such as biomass fuel, on structure integrity and safety for advanced heat resistant materials. Moreover, an evaluation of the degradation mechanism stress relaxation cracking [8-11] is aimed to be achieved. In addition, the obtained knowledge will facilitate the development of new materials for the new generation power plants with better performance with respect to temperature, pressure and environmental conditions.

The aims of this licentiate thesis are to increase the knowledge concerning:

1. tensile deformation, damage and cracking behaviour during very slow deformation 
2. influence of long term ageing on toughness of austenitic alloys for the future power plants.

Future work will cover the whole purpose of the research project and be finalized in a Ph.D. thesis. It will partly consist of further evaluation of the topics presented in this thesis. The long term ageing experiment will continue and is planned to last for 30000 hours, its influence on structure integrity and safety will be evaluated using impact toughness and fracture toughness tests. The stress relaxation cracking behaviour will be evaluated using mechanical and thermal testing. Cyclic corrosion tests will be performed to investigate how tough environment influence structure integrity and safety.

\subsection{Structure of the thesis}

This thesis consists of two parts:

- Part I: Background and Theory

- Part II: Papers Included

Part I, Background and Theory, cover an introduction of the research project to the reader, also aims and future work are presented. Then information concerning the austenitic alloys and experimental details follows. A summary of the included papers is provided the reader and finally the conclusions of the thesis are given.

Part II, Papers Included, is based on six papers and describes the main research that has been conducted in the project. 



\section{Austenitic alloys}

This chapter provides general information about the austenitic alloys addressed in this thesis, austenitic stainless steels and nickel-base alloys. The review will concentrate on the austenitic stainless steels.

\subsection{Austenitic stainless steels}

The main feature of stainless steels are their resistance to corrosion. They also possess high ductility and toughness over a wide range of temperatures and exhibit excellent high-temperature oxidation resistance [2, 12-15]. Stainless steels can be divided into five grades, ferritic, austenitic, martensitic, dual and multiphase, and precipitation hardening. Four of them are based on the characteristic crystallographic structure of the alloys in the grades, ferritic, austenitic, martensitic and dual phase. The fifth grade, precipitation hardening is based on the type of heat treatment used rather than microstructure [12-14]. Since this thesis only considers the chromium-nickel alloyed austenitic stainless steel, the other grades will not be covered in the review.

Austenitic stainless steels have a face-centred cubic (FCC) crystallographic structure. They are the most commonly used and the grade containing the largest number of alloys, of the stainless steel grades. Austenitic stainless steels possess great corrosion resistance, good creep resistance and excellent ductility, formability and toughness $[12-14,16,17]$. These materials exhibit no ductile to brittle transition temperature, except for austenitic stainless steels with very high content of nitrogen. In addition, they cannot be hardened by heat treatment but substantially hardened by cold work. Austenitic stainless steels have relatively low yield strength but higher work hardening 
rates compared with other stainless steel grades $[12,14]$. The alloys contains typically 16-26 wt.\% Cr, 8-25 wt.\% Ni and 0-6 wt.\% Mo, and are fully austenitic from well below RT to melting temperature $[12,14]$. These alloys are non-ferromagnetic due to their crystallographic structure and have greater heat capacity and thermal expansion, with lower thermal conductivity than other stainless steels grades [12].

\subsubsection{Main alloying elements}

Austenitic stainless steels are iron-based and the main alloying elements in these materials are chromium, nickel, manganese, molybdenum, titanium, niobium, carbon and nitrogen $[12,17]$.

Chromium is mainly added to obtain corrosion resistance, it reacts rapidly with oxygen which creates a protective layer of chromium oxide on the surface. If the amount of chromium is $12 \mathrm{wt} . \%$ or more the oxide layer will selfrepair if it gets damaged, because of the rapid reaction between chromium and oxygen [12].

Nickel stabilises the FCC structure in iron. Nickel increases the size of the austenitic field, while nearly eliminating body-centred cubic (BCC) ferrite structure from the iron-chromium-carbon alloys. Together with chromium it produces high-temperature strength and scaling resistance.

Manganese forms austenite and can be used to replace nickel. Manganese improves the solubility of nitrogen.

Molybdenum improves both the local and the general corrosion resistance. Molybdenum is a ferrite stabiliser and must therefore be balanced with austenitic stabilisers to maintain the austenitic structure. It improves the creep properties $[12,17]$.

Titanium stabilises the austenitic stainless steel against intergranular corrosion, if the carbon content is high. Titanium reacts more easily with carbon than chromium does, thus, titanium carbides are formed in preference to chromium carbides and localised reduction of chromium is prevented. It also greatly improves the creep strength [17].

Niobium creates carbides more easily than chromium and is therefore used for intergranular corrosion resistance [12]. A too great amount niobium may reduce the creep strength $[16,17]$.

Carbon additions stabilise the austenitic phase, but has a negative effect on corrosion resistance, due to the formation of chromium carbides. If the carbon content is below about $0.03 \mathrm{wt} . \%$, the carbides do not form and the steel is virtually all austenitic at room temperature [12].

Nitrogen additions stabilises the austenitic phase and strengthens the material through solid solution $[12,18]$, leading to enhanced creep life and 
low temperature yield strength. However, a too great amount of nitrogen will reduce the creep life of austenitic stainless steels [17].

The stacking-fault energy (SFE) in austenitic stainless steels is influenced by the alloying elements $[19,20]$. Chromium decreases the SFE with increasing content in the austenitic stainless steels, at least within the range of 10-26 at.\% chromium. Opposite to chromium, nickel increases the SFE in austenitic stainless steels, at least within the range of 8-20 at.\% nickel [20]. However, the influence of cobalt, manganese and niobium on the SFE in austenitic stainless steels depends on the amount of nickel. Cobalt decreases the SFE, and the decrease is stronger in alloys with high nickel content. Manganese decreases the SFE in alloys with $<16$ at.\% nickel content. Niobium strongly increases the SFE in alloys with low nickel content, but the increasing effect is weaker when increasing the nickel content [19]. In addition, the SFE influence deformation mechanisms as twinning and dislocation movement, twinning and dislocation mechanisms are further explained in section 3.1.

\subsubsection{Precipitation}

Austenitic stainless steels containing 18 wt.\% chromium and 12 wt.\% nickel should be fully austenitic at high temperatures. However, the addition of alloy elements may results in precipitation of carbides, nitrides and intermetallic phases. These precipitates may not be desirable since they can affect the mechanical and corrosion properties. Their appearances depend on the chemical compositions [12, 17, 21]. Only the most common precipitates in austenitic stainless steels will be considered in this section.

$M_{23} C_{6}$ is a carbide with FCC structure, usually containing chromium as the main metallic element $(\mathrm{M})$ but nickel, molybdenum and iron can be a substitute for chromium. It nucleates very easily and therefore it appears early in the precipitation process and it has been found after only $30 \mathrm{~min}$ at $750^{\circ} \mathrm{C}$ in an austenitic stainless steel. It can be located in grain boundaries (GBs), twin boundaries (TBs) and intragranular sites. $M_{23} C_{6}$ most often appears in GBs and is often connected to intergranular corrosion $[12,13,17]$.

$\sigma$-phase is an intermetallic phase with tetragonal structure, usually containing chromium and molybdenum [12, 13, 17, 21], but several other compositions have been reported [17]. It can appear after around 1000 hours ageing at temperatures around $700^{\circ} \mathrm{C}$. It can be located in GBs, TBs and intragranularly. This brittle intermetallic phase affects mechanical properties and influences the corrosion resistance by removing chromium and molybdenum from the matrix material $[12,17,21]$.

Laves phase has a hexagonal structure, it contains mostly of iron and molybdenum, a medium content of chromium and nickel and a small amount 
of Manganese and silicon. It precipitates intragranularly, often in small amounts, after 1000 hours ageing at temperatures between $600^{\circ} \mathrm{C}$ and $800^{\circ} \mathrm{C}$ $[12,17]$.

$G$ phase is a silicide with FCC structure, it mostly contains of nickel and it is titanium or niobium rich. It precipitates in GBs after less than 10 hours at temperatures between $700^{\circ} \mathrm{C}$ and $800^{\circ} \mathrm{C}$ and after longer time as intragranular precipitates $[12,17]$.

Other precipitates that may form in austenitic stainless steel are carbonitrides such as $N b C, N b N, T i C$ and $T i N$. These are carbides and nitrides with FCC structure and contains of niobium or titanium and carbon or nitrogen respectively [17].

\subsection{Nickel-base alloys}

Nickel-base alloys are widely used in high-temperature applications at temperatures between $650^{\circ} \mathrm{C}$ and $1100^{\circ} \mathrm{C}$, since nickel is stable in the $\mathrm{FCC}$ structure from room temperature up to the melting temperature. Nickel-base alloys possess great corrosion resistance, strength, creep and fatigue properties at elevated temperatures. They consist of many alloying elements, but most of the nickel-base alloys have $10-20 \mathrm{wt} . \%$ chromium, up to $8 \mathrm{wt} . \%$ aluminium and titanium, 5-10 wt.\% cobalt and small amounts of boron, zirconium and carbon. Optional common additives are molybdenum, tungsten and tantalum. The chromium content is enough to create a corrosion protective chromium oxide layer, at higher temperatures a corrosion protective aluminium oxide layer is formed. Nickel-base alloys have an austenitic matrix, called $\gamma \cdot \gamma^{\prime}$ is a hardening precipitate that may improve the mechanical properties at elevated temperatures due to the ordered FCC structure, it often contains of nickel, aluminium and titanium. Other precipitates that can appear are $\mathrm{M}_{23} \mathrm{C}_{6}$ and $\mathrm{M}_{6} \mathrm{C}$, which often occur at GBs [7, 22]. 


\section{3 \\ Microstructural mechanisms and phenomena}

In this chapter the main microstructural mechanisms and phenomena related to the included papers are covered.

\subsection{Deformation mechanisms}

The main plastic deformation mechanisms in the investigated austenitic alloys can be divided into two types, dislocation and twin controlled deformations. Since they influence the mechanical behaviour and are different in appearance, a review of these mechanisms is provided.

\subsubsection{Dislocation movement}

A dislocation is a lattice line defect and can be divided into two different basic types, edge and screw dislocations. Edge dislocations have the Burgers vector oriented normal to the dislocation line and screw dislocations has the Burgers vector parallel to the dislocation line. Unlike edge dislocations, screw dislocations don't have a unique slip plane but several potential slip planes. Thus, the screw dislocation possesses greater mobility than the edge dislocation [23, 24].

There are two basic types of dislocation movements that may generate plastic deformation, glide and climb movement. Glide occurs when the dislocation moves in the plane along the dislocation line and the Burgers vector and climb occurs when the dislocation moves out of the plane perpendicular to the Burgers vector. When many dislocations glide in the same slip plane 
it results in planar slip which is a common plastic deformation mechanism in austenitic alloys treated in this thesis $[15,23,25]$. If there is a great number of slip steps on closely spaced parallel slip planes, slip bands will be formed [23, 26, 27], also common in the investigated alloys [28, 29]. Screw dislocations can change from one slip plane to another, this is called crossslip, if many screw dislocations cross-slip it results in wavy slip [23-25]. The stacking-fault energy (SFE) influences the cross-slip mechanism. When the $\mathrm{SFE}$ is low, cross-slip is restricted so that barriers to dislocation movement remain effective to higher stress levels than in the material of higher SFE. Thus, when the SFE decreases the slip characters changes from wavy to planar mode [24]. In face-centre cubic (FCC) metals, as austenitic alloys, slip appears generally between one of the four close-packed $\{111\}$ planes and in one of the three $<110>$ directions. More than one slip system can be activate, which is called multi-directional slip. Activation of other slip systems is rarely observed [23, 24]. To activate a slip system a critical shear stress is required, this shear stress acting on a slip plane can be calculated as,

$$
\tau=\frac{F}{A} \cos \phi \cos \lambda
$$

Where $\tau$ is the resolved shear stress from the force $F$ acting on crosssection area $A, \phi$ is the angle between $F$ and the normal to the slip plane and $\lambda$ is the angle between $F$ and the slip direction. The quantity of $\cos \phi$ $\cos \lambda$ is called the Schmid factor [23, 27].

Dislocation climb is dependent on diffusion and is for that reason thermally activated and temperature dependent, when atoms diffuse it enables edge dislocations to move out of its original slip plane [23].

Temperature influences the energy that has to be provided for dislocations to surmount the obstacles they encounter during slip. If the conditions are sufficient, thermal vibrations of the crystal atoms may assist the dislocation to surmount obstacles at lower values of applied stress than that required at $0 \mathrm{~K}$. Thus, an increase in temperature, or a reduction in applied strain rate, will reduce the flow stress [23].

\subsubsection{Twinning}

Twins may occur during different processes depending on origin. Annealing twins nucleate during thermal processes [30], transformation twins come from phase transformation and deformation twins nucleate from deformation [3133]. This review will concentrate on the later type. 
Deformation twins are initiated by a certain shear stress, which is higher than the stress needed for growth of an existing twin. The twinning process effects a rotation of the lattice such that the atom position in the twin represent a mirror image of the atoms in the matrix material [24, 31, 32]. The angle of the boundary between matrix material and twin, called twin boundary, get due to the mirror rotation a certain value, in austenitic alloys often $60^{\circ}[31,32]$. For FCC metals the critical twinning stress for initiation of twins is slightly influenced by temperature and strain rate, where the critical twinning stress increases with increasing temperature and strain rate. However, SFE have a larger influence on the critical twinning stress and it increases with increasing SFE. Also the grain size influence the twinning, a larger grain shows much greater twinning density than a smaller grain [32].

Formation of each deformation twin leads to a certain shear strain. This will increase plasticity of the material if a large number of twins have been formed [31, 32, 34], which is called twinning induced plasticity (TWIP) [34].

\subsection{Softening phenomena}

During deformation at elevated temperatures the softening phenomena dynamic recovery (DRV) and dynamic recrystallization (DRX) may occur, both in hot working (strain rate range 1-100s $\mathrm{s}^{-1}$ ) and slow creep deformation (strain rates below $\left.10^{-5} \mathrm{~s}^{-1}\right)$. Signs of DRV and DRX both appear in the stress and strain curve during flow stress and in the microstructure, see Fig. 1. Some of the investigated alloys in this thesis have showed such signs of DRV and DRX, see paper I, II and III. The phenomena affects the mechanical properties at elevated temperatures and therefore some information is given.

\subsubsection{Dynamic recovery}

DRV is influenced by dislocation density, when the flow stress increases during the first stage of deformation and due to dislocation interaction and reproduction the rate of recovery increases when the dislocation density increases. At this stage low angle grain boundaries (LAGB $\gtrsim 5^{\circ}$ ) and subgrains develop in the microstructure $[23,35]$. This process involves glide and climb of the dislocations which form LAGB. Since climb involves diffusion a sufficient temperature for thermal activation of diffusion of point defects is needed. During DRV some dislocation annihilation occurs. DRV can be observed in the stress-strain curve, a steady-state flow stress will be obtained due to a dynamic equilibrium between the rates of recovery and hardening [35, 36]. In Fig. 1 (b) both DRV and DRX are active during the process of plastic 
flow [36].

\subsubsection{Dynamic recrystallization}

DRX may occur in alloys with low or medium SFE and initiates when a critical strain has been reached at elevated temperature. The critical strain for initiation of DRX not only depends on deformation rate and temperature but also on chemical composition and initial grain size [23, 35-38]. During DRX new grains originate at the old high angle grain boundaries but due to the continuous deformation of the material, the dislocation density of the new grains increases. This will reduce the driving force for further growth of the new grains, and eventually the growth will stop. Since DRX originates at existing high angle grain boundaries during straining, DRX may appear at boundaries as deformation bands [35]. Thus, DRX shows recrystallized grains in the microstructure often near or at high angle grain boundaries [35, 37], Fig. 1 (a) shows recrystallized grains in AISI 316L after slow tensile deformation. Other sign of DRX is the decreasing flow stress in the stress and strain curve $[35,36]$, shown in Fig. 1 (b).
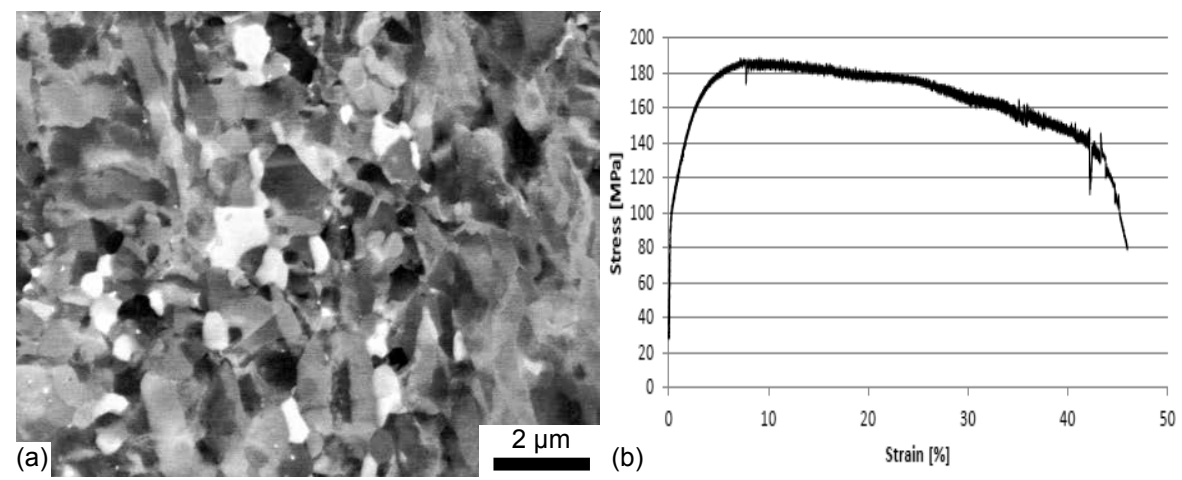

Figure 1: Recrystallized grain structure from DRX (a) and a stress and strain curve showing serrated yielding and the shape is due to DRV and DRX (b) in a slow strain rate tensile tested AISI $316 \mathrm{~L}$ at $650^{\circ} \mathrm{C}$ using a strain rate of $10^{-6} \mathrm{~s}^{-1}$ (based on paper II).

\subsection{Dynamic strain ageing}

Dynamic strain ageing (DSA) originates from interaction between solute atoms and dislocations during plastic deformation. Under plastic flow dislo- 
cations are gliding until they come across an obstacle where they are stationary until the obstacles are surmounted. When the dislocations are stationary solute atoms can diffuse towards the dislocations which result in an increase in the activation energy for re-activation and consequently also an increase in the stress needed for overcoming the obstacle [39-44]. Thus, DSA is directly influenced by the deformation rate that affects the mobility of the dislocations and the temperature that influences the diffusion rate of solute atoms. At temperatures below $350^{\circ} \mathrm{C}$ carbon is responsible for DSA while nitrogen and/or substitutional chromium atoms are responsible at higher temperatures $\left(400^{\circ} \mathrm{C}\right.$ to $\left.650^{\circ} \mathrm{C}\right)[18,29]$. It has been reported that mechanical properties like strength and ductility may be significantly changed due to DSA $[29,45]$. DSA is characterized by serrated yielding occurring in the stress-strain curve, denoted as Portevin-Le Châtelier (PLC) effect or jerky flow, Fig. 1 (b) show serrated yielding in AISI 316L. DSA can also lead to an increase in flow stress, work hardening rate and most important a negative strain rate sensitivity $[46,47]$ and DSA influence on ductility depends on the alloy composition $[15,46]$.

The PLC effect is created by the pinning and unpinning of dislocations and is recognized by serrated yielding in stress and strain curves [15, 48-50]. There are different types of PLC effects and they have designated appearance $[15,48,50]$. Type A is considered as locking serrations, they abruptly rise and then drop to a stress level below the general level. Type B is characterized by small oscillations about the general level of the curve. Type $\mathrm{C}$ leads to unlocking serration which is when the curve abrupt drops below the general stress level. Type D is characterized by plateaus on the curve [50]. Serrated yielding may also come from other mechanisms, e.g. twinning [24, 32]. 



\section{4}

\section{Experimental and analytical methods}

In this chapter, the conducted experimental and analytical methods are presented. The slow strain rate tensile testing (SSRT) using a strain rate of $10^{-6} \mathrm{~S}^{-1}$ and in-situ tensile tests were performed at Linköping University $(\mathrm{LiU})$ and most of the other mechanical tests were performed at AB Sandvik Materials Technology (SMT) in Sandviken, Sweden. All ageing and solution heat treatments have been done at SMT, except the ageing processes for the specimens used in paper IV which were performed at LiU. The microscopy analysis has mainly been performed at LiU but some of microstructural investigations have been made at SMT.

\subsection{Material}

All tested materials have been supplied by SMT in solution heat treatment conditions according to table 1. Five austenitic stainless steels (AISI 304, AISI 310, AISI 316L, Sanicro 25 and Sanicro 28,) and two nickel-base alloys (Alloy 617 and Alloy 800HT) have been used in the conducted experiments. The nominal chemical composition in $\mathrm{wt} \%$ for each alloy is presented in table 2. All the specimens were manufactured at SMT after the heat treatment, except the in-situ tensile specimens that were prepared at LiU.

\subsection{Tensile deformation}

Several uniaxial tensile tests have been performed within this project, different conditions as different temperatures and strain rates have been used. From tensile testing many mechanical properties can be obtained, e.g. tensile 


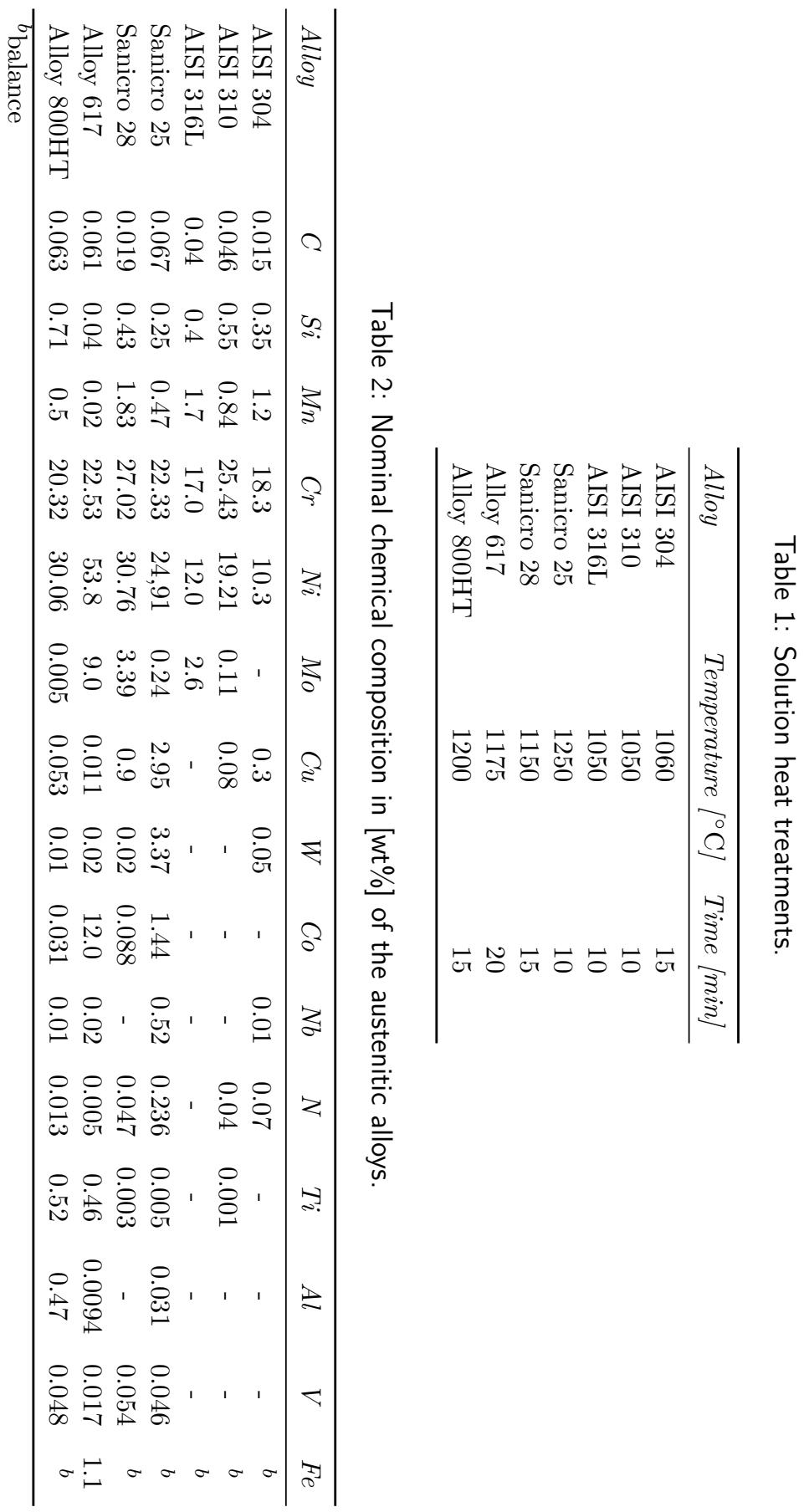


strength, elongation to fracture, etc., using the stress and strain curve to illustrate those properties. In this thesis only engineering stress and strain curves are considered. For the tensile testing a Roell-Korthaus and an Instron 5982 tensile test machine were used, the later is shown in Fig. 2. The machines were equipped with an MTS 653 furnace and a Magtec PMA-12/2/VV7-1 extensometer and an Instron SF16 furnace and an Instron 7361C extensometer respectively, both used in lab air environment. For the tensile tests roundbar specimens with a diameter of $5 \mathrm{~mm}$ and a gauge length of $50 \mathrm{~mm}$ were used.

The tensile tests were carried out at different conditions. Strain rate from $10^{-2} \mathrm{~S}^{-1}$ down to $10^{-6} \mathrm{~S}^{-1}$ and temperatures at $23^{\circ} \mathrm{C}$ referred to as room temperature $(\mathrm{RT}), 400^{\circ} \mathrm{C}, 500^{\circ} \mathrm{C}, 600^{\circ} \mathrm{C}, 650^{\circ} \mathrm{C}$ and $700^{\circ} \mathrm{C}$ were used. The SSRT was performed on the electromechanical tensile test machine showed in Fig. 2.

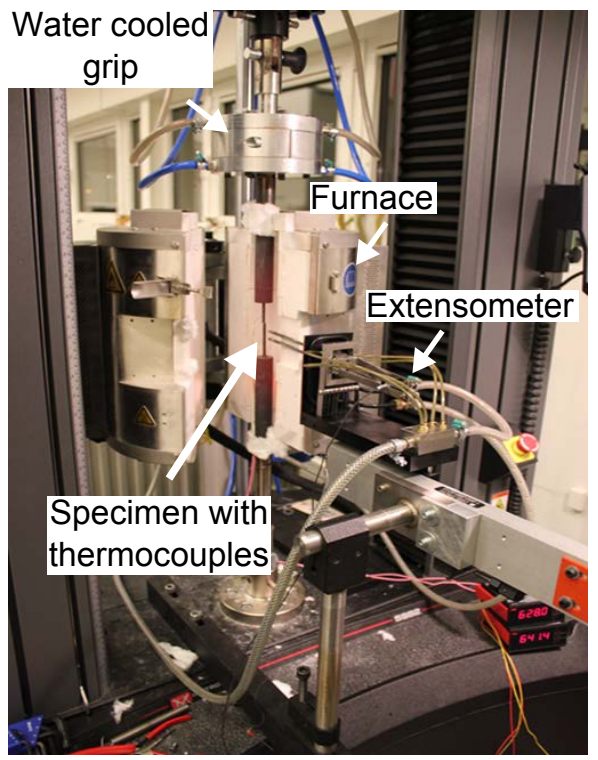

Figure 2: Electromechanical tensile test machine used for SSRT equipped with furnace, extensometer and water cooled grip.

The in-situ tensile testing was performed inside a HITACHI SU-70 FEGSEM scanning electron microscope (SEM) using a specially designed Gatan microtest tensile test stage, Fig. 3 (a) show the stage that is tilted $70^{\circ}$ for optimal diffraction. The miniature tensile stage can produce a force of maximum 5kN. A small specimen showed in Fig. 3 (b) was used. The thickness 
of the specimens were ground down to less than $1 \mathrm{~mm}$, then further preparation of one side of the specimen to enable the use of electron backscatter diffraction (EBSD). The procedure is described in detail under section 4.4.1 later in this chapter.
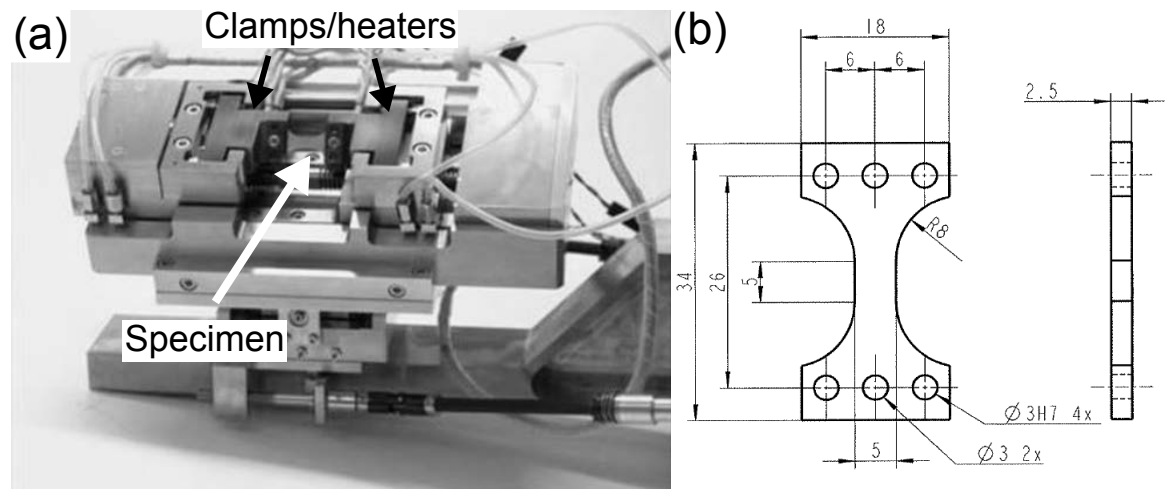

Figure 3: Miniature tensile test stage (a) and a drawing of the small specimen used for in-situ tensile test (b).

\subsection{Impact toughness testing}

The impact toughness tests were performed using the Charpy V method according to ISO 14556 standard. Samples with a dimension of 10x10x55mm and $\mathrm{V}$ type were used. The specimens were aged at $650^{\circ} \mathrm{C}$ and $700^{\circ} \mathrm{C}$ in air environment for 1000 and 3000 hours before the toughness tests. The impact toughness testing have been performed at room temperature, two to three specimens at each ageing condition and non-aged specimens were tested.

\subsection{Microscopy}

\subsubsection{Specimen preparation}

To enable the use of electron channeling contrast imaging and electron backscatter diffraction, a careful specimen preparation must be performed. Both techniques are surface sensitive due to scattering of the backscattered electrons. Thus, it is crucial to minimize the surface roughness before the microscopy. Both electrolyte and mechanical polishing can accomplish the critical surface preparation, in this project only the later one has been used according to the following steps: 
1. $500 \mathrm{SiC}$-paper $(30 \mu \mathrm{m}), 2 \mathrm{~min}$

2. $1200 \mathrm{SiC}$-paper $(15 \mu \mathrm{m}), 2 \mathrm{~min}$

3. $4000 \mathrm{SiC}$-paper $(5 \mu \mathrm{m}), 3 \mathrm{~min}$

4. Silk cloth, diamond suspensions $(3 \mu \mathrm{m}), 5 \mathrm{~min}$

5. Woven wool cloth, diamond suspensions $(1 \mu \mathrm{m})$, lubricant, $10 \mathrm{~min}$

6. Rayon-viscose fibres cloth, diamond suspensions $(0,25 \mu \mathrm{m})$, lubricant, $15 \mathrm{~min}$

7. Neoprene foam cloth, colloidal silica suspension $(0,04 \mu \mathrm{m}), 5 \mathrm{~min}$

8. Neoprene foam cloth, water, $1 \mathrm{~min}$

After each step, specimens and holder were cleaned carefully using water and ethanol for step 1-2, and water + detergent, ethanol and ultrasonic cleaning for step 3-9.

\subsubsection{Scanning electron microscopy}

The microstructural investigations were performed using different SEM related techniques like electron channeling contrast imaging (ECCI), electron backscatter diffraction (EBSD) and energy-dispersive system (EDS).

To capture deformation, damage and even dislocation and twin structures in the highly deformed alloys, the ECCI technique was used [51, 52]. In 1967 Coates [53] reported that the intensity of backscattered electrons is strongly dependent on crystal orientation in the scanning electron microscope. The same year, Booker et al. [54] suggested that the effect could be used to image crystal defects near the surface of a bulk specimen using a SEM, since close to the Bragg condition the backscattered electron intensity varies rapidly with orientation. This forms the basis of the technique now called ECCI. Thus, ECCI uses the interaction between backscattered electrons and the crystal planes to generate contrast resulting in an image where local misorientation, defects and strain fields are shown as contrast variations [52-57]. Fig. 4 shows the sample position perpendicular to the incident electron beam in the ECCI set up. Gutierrez-Urrutia et al. [52] studied dislocation structures and deformation twins using the ECCI and EBSD techniques in a SEM and bright-field transmission electron microscopy of the same area in a tensile deformed TWIP steel. They found that ECCI could image dislocation cell structures and mechanical twins of $30 \mathrm{~nm}$ thickness. Thus, ECCI is a 
powerful tool in characterizing highly deformed alloys. Fig. 5 shows dislocation structure and deformation as a plastic zone in front of a crack tip and slip bands in an austenitic alloy, using the ECCI technique. Moreover, the acceleration voltage influences the contrast in ECCI micrographs, where decreasing acceleration voltage improves the contrast, according to GutierrezUrrutia et al. [52] there are two main possible reasons for this. First reason, the backscatter yield increases with decreasing acceleration voltage, which gives that the parts with higher intensity appear brighter while parts with low intensity maintain dark. Second reason, the interaction volume decreases with decreasing acceleration voltage, the lattice strain shows smaller variations in a smaller volume, thus diffraction conditions and contrast are better defined. ECCI investigations were performed on a HITACHI SU-70 field emission gun (FEG)-SEM and a Zeiss XB 1540 FEG-SEM, both equipped with a solid state 4-quadrant backscattered electron (BSE) detector, using $10 \mathrm{kV}$ acceleration voltage and working distances between $5 \mathrm{~mm}$ to $7 \mathrm{~mm}$ $[52,58]$.

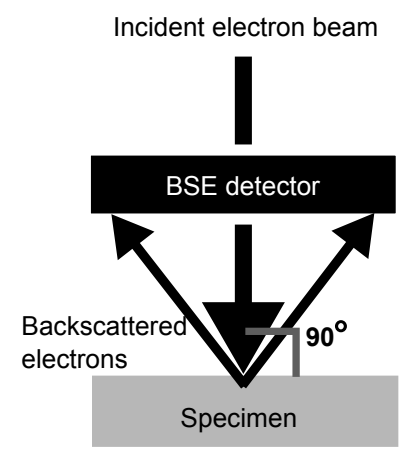

Figure 4: $\mathrm{ECCl}$ set up with the incident electron beam $90^{\circ}$ angled to the specimen, based on Gutierrez-Urrutia et al. [52].

The EBSD technique provides information about phases and crystallographic orientation, using Kikuchi patterns. As a simple analogy the grains in a polycrystalline alloy act as a mirror reflecting it's orientation to the observers camera. Determination of characteristic crystallographic parameters as crystal plane spacing and angles between planes allow the phaseidentification. Crystallographic orientations are determined by identification of the Kikuchi pattern [58-60]. To use EBSD the specimen has to be tilted around $70^{\circ}$ against the incident electron beam to provide the optimal diffraction $[58,60]$. EBSD can be used to evaluate plastic deformation, because the degree of deformation or damage can be expressed as local crystal reorienta- 

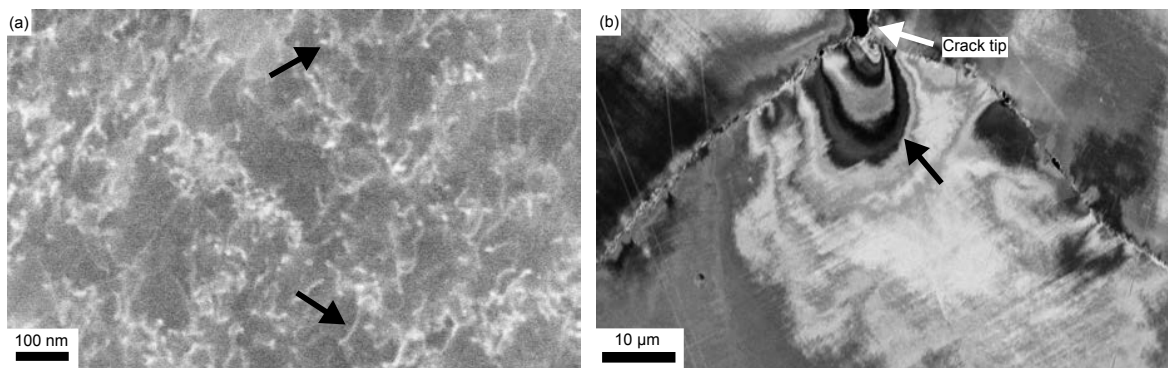

Figure 5: Dislocations and dislocation ends in Sanicro 25 (a) and plastic zone in front of a crack tip, slip bands and local strain concentrations at grain boundaries in Alloy 617 (b).

tions of grains [60-62]. Also, the grain average misorientation (GAM) has a linear relationship with plastic strain $[60,62]$. Information about active slip systems in the microstructure can be provided by the EBSD technique, using obtained Euler angles and Equation 1 showed in section 3.1.1 [63]. EBSD investigations were performed in a HITACHI SU-70 FEG-SEM equipped with an OXFORD EBSD detector and a 6500 F JEOL FEG-SEM equipped with a TSL OIM EBSD system, both EBSD systems used the HKL software CHANNEL 5. The EBSD-maps were measured at $15 \mathrm{kV}$ and $20 \mathrm{kV}$ acceleration voltage using a working distance of $12 \mathrm{~mm}$ up to $25 \mathrm{~mm}$ and step sizes of 0,1 $\mu \mathrm{m}$ up to $4 \mu \mathrm{m}$ were used $[58,60]$.

The EDS technique provides chemical compositional information of the specimen [58]. It is mainly used to collect information about precipitation that occurs during the ageing and the long deformation process of SSRT. The EDS investigations were performed using both a HITACHI SU-70 FEG-SEM and a 6500 F JEOL FEG-SEM. 



\section{5 \\ Summary of appended papers}

\section{Paper I}

Deformation and damage behaviours of austenitic alloys in the dynamic strain ageing regime

The purpose of this paper was to investigate the deformation and damage mechanisms related to dynamic strain ageing (DSA) in three austenitic stainless steels (AISI 310, AISI 316L and Sanicro 25) and two nickel-base alloys (Alloy 617 and Alloy 800HT). The materials were investigated by tensile testing at different elevated temperatures $\left(400^{\circ} \mathrm{C}\right.$ to $\left.700^{\circ} \mathrm{C}\right)$. One of the materials was low cycle fatigue $(\mathrm{LCF})$ tested at $650^{\circ} \mathrm{C}$ using a strain range of $1,2 \%$. Since DSA is present in different temperature ranges depending on alloy composition, a scanning electron microscope (SEM) investigation was mainly performed on the specimens tested at $650^{\circ} \mathrm{C}$ and $700^{\circ} \mathrm{C}$ where all five materials displayed DSA.

As expected deformation in the DSA regime is planar slip and slip bands in single and multi-direction. Local damage has been connected to interaction between slip bands and/or interaction between twins and grain boundaries. Ductility is affected differently by temperature depending on alloy tested, DSA is not always related to a low ductility of the material, it is suggested that DSA may introduce a phenomenon similar to twinning induced plasticity (TWIP) that could increase the ductility. 


\section{Paper II}

\section{Influence of deformation rate on mechanical response of an AISI 316L austenitic stainless steel}

This paper investigates the high-temperature behaviour during uniaxial slow strain rate tensile testing of an AISI 316L material, commonly used for components in power plants. Uniaxial slow strain rate tensile testing (SSRT) has been performed at different temperatures up to $700^{\circ} \mathrm{C}$ using strain rates down to $10^{-6} \mathrm{~S}^{-1}$. An investigation of the microstructure was conducted on the deformed and fractured materials using mainly the scanning electron microscopy methods, electron channeling contrast imaging (ECCI) and electron backscatter diffraction (EBSD), to capture the microstructural mechanisms coupled to the mechanical behaviours seen in engineering stress-strain curves.

It was found that DSA occurs in AISI 316L during tensile testing at temperatures of $650^{\circ} \mathrm{C}$ and $700^{\circ} \mathrm{C}$ when using a strain rate of $10^{-6} \mathrm{~s}^{-1}$. The strength decreases with increasing temperature and decreasing strain rate. Elongation on the other hand increases with decreasing strain rate applied at the same temperature, this has been observed at both room temperature (RT) and elevated temperature (up to $700^{\circ} \mathrm{C}$ ). Dynamic recrystallization (DRX) can occur during tensile deformation at elevated temperature. At a low strain rate $\left(10^{-6} \mathrm{~S}^{-1}\right)$ DRX are more homogeneously spread in the microstructure. The presence of dynamic recovery together with dynamic recrystallization can be seen to effect the appearance of the stress-strain curves at $650^{\circ} \mathrm{C}$ and $700^{\circ} \mathrm{C}$ when using a low strain rate.

\section{Paper III}

Mechanical behaviours of Alloy 617 with varied strain rates at high temperatures

This study focuses on the deformation and damage mechanisms in Alloy 617 deformed using low strain rates (down to $10^{-6} \mathrm{~S}^{-1}$ ) at elevated temperatures $\left(650^{\circ} \mathrm{C}\right.$ and $\left.700^{\circ} \mathrm{C}\right)$ by uniaxial SSRT and microstructure evaluation using scanning electron microscopy techniques as ECCI.

DSA can occur in Alloy 617 at temperatures between $650^{\circ} \mathrm{C}$ and $700^{\circ} \mathrm{C}$ with strain rate from $10^{-2} \mathrm{~s}^{-1}$ down to $10^{-6} \mathrm{~S}^{-1}$. TWIP is one of the mechanisms for a high elongation during DSA. Both strength and elongation increase with decrease of strain rate down to $10^{-4} \mathrm{~S}^{-1}$, and then both decrease with further decrease of strain rate. Micro and nano DRX can occur during 
the tensile deformation with very low strain rates. Repeated DRX can lead to the formation of damage in the material.

\section{Paper IV}

\section{Damage and Fracture Behaviours in Aged Austenitic Materials During High-Temperature Slow Strain Rate Testing}

The aim of this study was to investigate damage and fracture mechanisms of high-temperature long term aged austenitic materials (the austenitic stainless steel AISI 304 and the nickel-base alloy Alloy 617) during uniaxial SSRT at RT and elevated temperature. The role of precipitation from hightemperature ageing and the long deformation process is evaluated by microscopy and coupled to the damage and fracture behaviour.

The investigation showed that SSRT caused intergranular cracking in both high-temperature long term aged AISI 304 and Alloy 617 at both RT and $700^{\circ} \mathrm{C}$ when using a strain rate of $10^{-6} \mathrm{~S}^{-1}$. At RT the fracture is caused by cracks initiated due to stress concentration formed by the precipitates from the ageing process in the grain boundaries (GBs) for both alloys. Alloy 617 also exhibit crack initiation and propagation by slip band interaction with the small GB precipitates. At $700^{\circ} \mathrm{C}$ the fracture is caused by GB precipitates formed during both the ageing process and the tensile deformation. Elongation to fracture decreases for both the aged stainless steel and the aged nickel-base alloy when a lower strain rate is used compared with a higher strain rate at $700^{\circ} \mathrm{C}$.

\section{Paper V}

Advanced Microstructure Studies of an Austenitic Material Using EBSD in Elevated Temperature In-Situ Tensile Testing in SEM

In this study in-situ tensile testing was performed on Sanicro 25 at two different temperatures. An investigation of the influence of temperature on the deformation behaviour was performed using the EBSD technique. Fracture behaviour will also be discussed.

The analysis from in-situ tensile test at RT and $300^{\circ} \mathrm{C}$ in a SEM together with EBSD in Sanicro 25 has shown that larger grains may tend to accumulate more local plastic strain for the same macroscopic strain values at 
both temperatures. Somewhat higher plastic strains at grain level can be obtained at RT compared to elevated temperature for the same macroscopic strain value. Cracks initiate and propagate along the slip system(s) with the highest Schmid factor at RT.

\section{Paper VI}

\section{Influence of High Temperature Ageing on the Toughness of Ad-} vanced Heat Resistant Materials

In this paper the influence of precipitation and growth of precipitates on toughness due to different chemical compositions and high-temperature treatment are investigated. The experiments were conducted on two austenitic stainless steels (AISI 304 and Sanicro 28) and one nickel-base alloy (Alloy 617). Impact toughness tests have been performed and the fracture surface and cross-section have been investigated using microscopy. Thermocalc has been used to predict possible precipitates.

From the study it was found that the fracture initiation and propagation in the aged austenitic stainless steel is very local. The initiation and propagation of fracture behave differently in these materials due to different chemical compositions affecting nucleation, growth and shape of precipitates. The brittle $\sigma$-phase can appear in the austenitic stainless steel after 1000 hours at $650^{\circ} \mathrm{C}$ and then increases in amount. The amount and shape have strong effect on the fracture behaviour, where needle shaped $\sigma$-phase which mostly appear at high temperature $\left(700^{\circ} \mathrm{C}\right)$ after longer ageing time (3000 hours) lead to a low impact toughness and brittle fractures both locally and on a macro-level in the specimen. The nickel-base alloy show higher impact toughness with increasing ageing temperature and time. 


\section{6}

\section{Conclusions}

The presented research within this licentiate thesis deals with high-temperature behaviour of austenitic alloys, five austenitic stainless steels and two nickelbase alloys, with focus on deformation, damage and fracture behaviour during slow strain rate deformation and the influence of long term ageing.

It was found that the main deformation mechanisms in the austenitic alloys are planar dislocation deformation, such as planar slip, slip bands in single and multi-direction. Twinning has also been observed and related to the dynamic strain ageing phenomenon, dynamic strain ageing occurred in all tested materials but at different temperature ranges. The plastic performance of the austenitic alloys is influenced differently by temperature when subjected to tensile deformation. Dynamic strain ageing may not always lead to a lower ductility of the material, it is suggested that dynamic strain ageing may introduce a phenomenon similar to twinning induced plasticity that could increase the ductility. However, the ductility performance of some of the tested austenitic alloys increased when subjected to a slow strain rate tensile deformation process at elevated temperatures compared when using a higher deformation rate at the same temperature. While others showed an increase in ductility when decreasing to a certain deformation rate and then the ductility performance decreased with further decreasing deformation rate. During these tests softening processes, such as dynamic recovery and dynamic recrystallization appeared in some of the tested alloys, both in stainless steel and nickel-base alloy. In aged conditions the tested austenitic alloys showed only a decrease in ductility with decreasing deformation rate. This is attributed to the formation of precipitates in the grain boundaries creating stress concentration that causes intergranular fracture. Also, in some of these specimens dynamic recrystallization was observed.

The analysis from electron backscatter diffraction and in-situ tensile test 
in a scanning electron microscope at room temperature and elevated temperature in Sanicro 25 has shown that, larger grains may tend to accumulate more local plastic strain for the same macroscopic strain values at both temperatures. Somewhat higher plastic strains at grain level can be obtained at room temperature than at elevated temperature for the same macroscopic strain value. Cracks initiate and propagate along the slip systems with the highest Schmid factor at room temperature.

Local damage has been connected to interaction between slip bands and/or interaction between twins and grain boundaries. Repeated dynamic recrystallization may also lead to the formation of damage.

It has also been found that the fracture initiation and propagation in the aged austenitic stainless steel is very local during impact testing. The initiation and propagation of fracture behave differently in the austenitic alloys due to different chemical compositions affecting nucleation, growth and shape of the precipitates. The brittle $\sigma$-phase can appear in the austenitic stainless steels AISI 304 and Sanicro 28 after 1000 hours at $650^{\circ} \mathrm{C}$ and then increases in amount. The amount and shape have strong effect on the fracture behaviour, where needle shaped $\sigma$-phase which mostly appear at high temperature $\left(700^{\circ} \mathrm{C}\right)$ after longer ageing time (3000 hours) lead to a low impact toughness and brittle fractures both locally and on a macro-level in the specimen. However, the tested nickel-base alloy showed higher impact toughness with increasing ageing temperature and time. 


\section{Bibliography}

[1] M. Calmunger. Effect of temperature on mechanical response of austenitic materials. Master's thesis, Linköping University, 2011.

[2] P. Viklund, A. Hjörnhede, P. Henderson, A. Stålenheim, and R. Pettersson. Corrosion of superheater materials in a waste-to-energy plant. Fuel Processing Technology, 105:106-112, 2013.

[3] A.K.M. Sadrul Islama and M. Ahiduzzaman. Biomass energy: Sustainable solution for greenhouse gas emission. AIP Conference Proceedings, 1440:23-32, 2012.

[4] J. Pettersson, H. Asteman, J.-E. Svensson, and L.-G. Johansson. KCL induced corrosion of a 304-type austenitic stainless steel at $600{ }^{\circ} \mathrm{C}$; the role of potassium. Oxidation of Metals, 64:23-41, 2005.

[5] L. Trygg and S. Amiri. European perspective on absorption cooling in a combined heat and power system - A case study of energy utility and industries in sweden. Applied Energy, 84:1319-1337, 2007.

[6] J. Yin and Z. Wu. Corrosion behavior of TP316L of superheater in biomass boiler with simulated atmosphere and deposit. Chinese Journal of Chemical Engineering, 17:849-853, 2009.

[7] R. C. Reed. The Superalloys Fundamentals and Applications. Cambridge University Press, 2008.

[8] J. G. Nawrocki, J. N. DuPont, C. V. Robino, J. D. Puskar, and A. R. Marder. The mechanism of stress-relief cracking in a ferritic alloy steel. Welding Journal (Miami, Fla), 82:25-35, 2003.

[9] D. J. Benac, D. B. Olson, and M. Urzendowski. High-temperature stress relaxation cracking and stress rupture observed in a coke gasifier failure. Journal of Failure Analysis and Prevention, 11:251-264, 2011. 
[10] M. Turski, P. J. Bouchard, A. Steuwer, and P. J. Withers. Residual stress driven creep cracking in AISI Type 316 stainless steel. Acta Materialia, 56:3598-3612, 2008.

[11] Q. Auzoux, L. Allais, C. Caës, B. Girard, I. Tournié, A.F. Gourgues, and A. Pineau. Intergranular damage in AISI $316 \mathrm{~L}(\mathrm{~N})$ austenitic stainless steel at $600^{\circ} \mathrm{C}$ : Pre-strain and multiaxial effects. Nuclear Engineering and Design, 235:2227-2245, 2005.

[12] J. R. Davis, editor. Stainless Steels. ASM International, 2004.

[13] G. Krauss. STEELS Processing, Structure, and Performance. ASM International, 2005.

[14] F. B. Pickering. Physical mettallurgical developments of stainless steels. Stainless Steels, 84:2-28, 1985.

[15] I. Nikulin and R. Kaibyshev. Deformation behavior and the portevin-le chatelier effect in a modified $18 \mathrm{Cr}-8 \mathrm{~N}$ stainless steel. Materials Science and Engineering A, 528:1340-1347, 2011.

[16] V. Vodárek. Creep behavior and microstructural evolution in AISI $316 \mathrm{LN}+\mathrm{Nb}$ steels at $650^{\circ} \mathrm{C}$. Materials Science and Engineering A, 528:4232-4238, 2011.

[17] T. Sourmail. Precipitation in creep resistant austenitic stainless steels. Materials Science and Technology, 17:1-14, 2001.

[18] G. V. P. Reddy, R. Sandhya, K. B. S. Rao, and S. Sankaran. Influence of nitrogen alloying on dynamic strain ageing regimes in low cycle fatigue of AISI 316LN stainless steel. Procedia Engineering, 2:2181-2188, 2010.

[19] S. Lu, Q.-M. Hub, B. Johansson, and L. Vitos. Stacking fault energies of $\mathrm{Mn}, \mathrm{Co}$ and $\mathrm{Nb}$ alloyed austenitic stainless steels. Acta Materialia, 59:5728-5734, 2011.

[20] L. Vitos, J.-O. Nilsson, and B. Johansson. Alloying effects on the stacking fault energy in austenitic stainless steels from first-principles theory. Acta Materialia, 54:3821-3826, 2006.

[21] M. Schwind, J. Källqvist, J.-O. Nilsson, J. Ågren, and H.-O. Andrén. $\sigma$-phase precipitation in stabilized austenitic stainless steels. Acta $\mathrm{Ma}$ terialia, 48:2473-2481, 2000. 
[22] C. T. Sims, N. S. Stoloff, and W. C. Hagel, editors. Superalloys II. John Wiley \& sons, 1987.

[23] D. Hull and D. J. Bacon. Introduction to Dislocations. ButterworthHeinmann, 2007.

[24] R. W. Hertzberg. Deformation and Fracture Mechanics of Engineering Materials. John Wiley \& sons, 1995.

[25] V. Gerold and H.P. Karnthaler. On the origin of planar slip in f.c.c. alloys. Acta Metallurgica, 37:2177-2183, 1989.

[26] J. C. Fisher, E. W. Hart, and R. H. Pry. Theory of slip-band formation. Phys. Rev., 87:958-961, 1952.

[27] P. Villechaise, L. Sabatier, and J. C. Girard. On slip band features and crack initiation in fatigued 316L austenitic stainless steel: Part 1: Analysis by electron back-scattered diffraction and atomic force microscopy. Materials Science and Engineering: A, 323:377-385, 2002.

[28] H. Mughrabi and H.-J. Christ. Cyclic deformation and fatigue of selected ferritic and austenitic steels: Specific aspects. ISIJ International, 37: 1154-1169, 1997.

[29] S.-G. Hong and S.-B. Lee. Mechanism of dynamic strain aging and characterization of its effect on the low-cycle fatigue behavior in type 316L stainless steel. Journal of Nuclear Materials, 340:307-314, 2005.

[30] Y. Jin, M. Bernacki, G.S. Rohrer, A.D. Rollett, B. Lin, and N. Bozzolo. Formation of annealing twins during recrystallization and grain growth in 304L austenitic stainless steel. Materials Science Forum, 753:113-116, 2013.

[31] J. W. Christian and S. Mahajan. Deformation twinning. Progress in Materials Science, 39:1-157, 1995.

[32] M. A. Meyers, O. Vhringer, and V. A. Lubarda. The onset of twinning in metals: a constitutive description. Acta Materialia, 49:4025-4039, 2001.

[33] F. K. Yan, G. Z. Liu, N .R. Tao, and K. Lu. Strength and ductility of 316L austenitic stainless steel strengthened by nano-scale twin bundles. Acta Materialia, 60:1059-1071, 2012. 
[34] O. Grässel, L. Krüger, G. Frommeyer, and L. W. Meyer. High strength Fe-Mn-(Al, Si) TRIP/TWIP steels development - properties - application. International Journal of Plasticity, 16:1391-1409, 2000.

[35] F. J. Humphreys and M. Hatherly. Recrystallization and Related Annealing Phenomena. Elsevier Science \& Technology Books, 1996.

[36] W. Roberts and B. Ahlblom. A nucleation criterion for dynamic recrystallization during hot working. Acta Metallurgica, 26:801-813, 1978.

[37] D. Samantaray, S. Mandal, C. Phaniraj, and A. K. Bhaduri. Flow behavior and microstructural evolution during hot deformation of AISI Type $316 \mathrm{~L}(\mathrm{~N})$ austenitic stainless steel. Materials Science and Engineering A, 528:8565-8572, 2011.

[38] E. I. Poliak and J. J. Jonas. A one-parmenter approach to determining the critical conditions for the initiation of dynamic recrystallization. Acta Materialia, 44:127-136, 1996.

[39] L. H. de Almeida, I. Le May, and P. R. O. Emygdio. Mechanistic modeling of dynamic strain aging in austenitic stainless steels. Materials Characterization, 41:137-150, 1998.

[40] M. Hörnqvist and B. Karlsson. Temperature and strain rate dependence of the dynamic strain aging effect in an Al-Zn-Mg alloy. Materials Science and Technology, 22:213-222, 2006.

[41] A. Van Den Beukel. On the mechanism of serrated yielding and dynamic strain ageing. Acta Metallurgica, 28:965-969, 1980.

[42] A. W. Sleeswyk. Slow strain-hardening of ingot iron. Acta Metallurgica, 6:598-603, 1958.

[43] R. A. Mulford and U. F. Kocks. New observations on the mechanisms of dynamic strain aging and of jerky flow. Acta Metallurgica, 27:1125-1134, 1979.

[44] G. V. P. Reddy, R. Sandhya, M. Valsan, and K. B. S. Rao. Temperature dependence of low cycle fatigue of $316(\mathrm{~N})$ weld metals and $316 \mathrm{~L}(\mathrm{~N}) / 316(\mathrm{~N})$ weld joints. Materials science and technology, 26:1384 $-1392,2010$.

[45] S. L. Mannan, K. G. Samuel, and P. Rodriguez. Influence of temperature and grain size on the tensile ductility of AISI 316 stainless steel. Materials Science and Engineering, 68:143-149, 1985. 
[46] G. Chai. IAS 2008. In Influence of nitrogen content on the static and dynamic strain ageing in super duplex stainless steels, 2008.

[47] G. R. Stewart and J. J. Jonas. Static and dynamic strain aging at high temperatures in 304 stainless steel. ISIJ International, 44:1263-1272, 2004.

[48] W. Karlsen, M. Ivanchenko, U. Ehrnstén, Y. Yagodzinskyy, and H. Hänninen. Microstructural manifestation of dynamic strain aging in AISI 316 stainless steel. Journal of Nuclear Materials, 395:156-161, 2009.

[49] M. C. Cai, L. S. Niu, T. Yu, H. J. Shi, and X. F. Ma. Strain rate and temperature effects on the critical strain for Portevin-Le Châtelier effect. Materials Science and Engineering A, 527:5175-5180, 2010.

[50] M. Ivanchenko. Dynamic strain aging of austenitic stainless steels and Ni-base alloys. PhD thesis, Aalto University, 2010.

[51] J. J. Moverare, S. Johansson, and R. C. Reed. Deformation and damage mechanisms during thermal-mechanical fatigue of a single-crystal superalloy. Acta Materialia, 57:2266-2276, 2009.

[52] I. Gutierrez-Urrutia, S. Zaefferer, and D. Raabe. Electron channeling contrast imaging of twins and dislocations in twinning-induced plasticity steels under controlled diffraction conditions in a scanning electron microscope. Scripta MATERIALIA, 61:737-740, 2009.

[53] D. G. Coates. Kikuchi-like reflection patterns obtained with the scanning electron microscope. Philosophical Magazine, 16:1179-1184, 1967.

[54] G. R. Booker, A. M. B. Shaw, M. J. Whelan, and P. B. Hirsch. Some comments on the interpretation of the 'kikuchi-like reflection patterns' observed by scanning electron microscopy. Philosophical Magazine, 16: 1185, 1967.

[55] M. A. Crimp. Scanning electron microscopy imaging of dislocations in bulk materials, using electron channeling contrast. Microscopy Research and Technique, 69:347-381, 2006.

[56] A. J. Wilkinson and P. B. Hirsch. Electron diffraction based techniques in scanning electron microscopy of bulk materials. Micron, 28:279-308, 1997. 
[57] I. Gutierrez-Urrutia and D. Raabe. Dislocation and twin substructure evolution during strain hardening of an Fe-22wt.\% Mn-0.6wt.\% C TWIP steel observed by electron channeling contrast imaging. Acta Materialia, 59:6449-6462, 2011.

[58] J. Goldstein, D. E. Newbury, D. C. Joy, C. E. Lyman, P. Echlin, E. Lifshin, L. Sawyer, and J. R. Michael. Scanning Electron Microscopy and X-Ray Microanalysis. Springer, 2002.

[59] O. Engler and V. Randle. Introduction to texture analysis. CRC Press Inc, 2009.

[60] J. A. Schwartz, K. Mukul, A. L. Brent, and D. P. Field. Electron Backscattering Diffraction in Material Science. Springer Science + Business Media, 2009.

[61] S. I. Wright, M. M. Nowell, and D. P. Field. A review of strain analysis using electron backscatter diffraction. Microscopy and Microanalysis, 17:316-329, 2011.

[62] R. Yoda, T. Yokomaku, and N. Tsuji. Plastic deformation and creep damage evaluations of type 316 austenitic stainless steels by EBSD. Materials Characterization, 61:913-922, 2010.

[63] N. Jia, R. Lin Peng, G. C. Chai, S. Johansson, and Y. D. Wang. Direct experimental mapping of microscale deformation heterogeneity in duplex stainless steel. Materials Science and Engineering A, 491:425-433, 2008. 


\section{Part II}

\section{Papers Included}

The articles associated with this thesis have been removed for copyright reasons. For more details about these see:

http://urn.kb.se/resolve?urn=urn:nbn:se:liu:diva-98242 